\title{
Faktor-Faktor yang Berhubungan dengan Kepatuhan Berobat Pada Penderita Tuberkulosis Paru
}

\author{
Factors Related to Medication Adherence in Pulmonary Tuberculosis Patients
}

\author{
Ulfah $^{1,2}$, Cicilia Windiyaningsih ${ }^{2}$, Zainal Abidin ${ }^{2}$, Farida Murtiani ${ }^{3}$ \\ ${ }^{1}$ Puskesmas Cipunegara, ${ }^{2}$ Program Pasca Sarjana IImu Kesehatan Masyarakat Universitas \\ Respati Indonesia, ${ }^{3}$ Rumah Sakit Penyakit Infeksi Prof. Dr Sulianti Saroso
}

Korespodensi Penulis :

Ulfah

Email: ulfahydermawan@gmail.com

\begin{abstract}
Abstrak
Latar Belakang: Kepatuhan pasien dalam minum obat merupakan faktor penting dalam keberhasilan suatu pengobatan TB paru. Tingginya angka putus berobat mengakibatkan tingginya kasus resisten obat. Metode: desain studi kasus kontrol (Case Control Study) menggunakan data primer dan sekunder. Sampel penelitian ini adalah seluruh pasien TB Paru yang berobat di Puskesmas Cipunagara Tahun 2015 sampai Juni 2017. Besar sampel 68 yang terdiri dari 84 kasus dan 84 kontrol yang diambil dengan teknik consecutive sampling. Analisis data dilakukan secara univariat, bivariat dengan uji chi square dan multivariat dengan regresi logistik berganda. Hasil: faktor yang berhubungan dengan kepatuhan pengobatan TB paru adalah dukungan keluarga (Pvalue $=0.003$; $\mathrm{OR}=2,956$ ), jenis kelamin ( $P$ value $=0,045$; $\mathrm{OR}=1,961$ ), pendidikan (Pvalue $=0,045 ; \mathrm{OR}=1,962)$, pekerjaan ( $\mathrm{P}$ value=0.043; $\mathrm{OR}=1,989)$, pengetahuan (Pvalue=0,005; OR=2,529), efek samping obat ( Pvalue=0,045; OR=1,961), peran PMO (Pvalue=0,000; $\mathrm{OR}=3,500$ ), jarak fasilitas kesehatan (Pvalue $=0,044$; $\mathrm{OR}=1,967$ ), sikap petugas ( $\mathrm{Pvalue}=0,020$; $\mathrm{OR}=2,172)$. Faktor yang tidak berhubungan dengan kepatuhan pengobatan TB paru adalah pendapatan (Pvalue=0,164) dan usia (Pvalue=0.535). Kesimpulan: faktor dominan yang berhubungan dengan kepatuhan pengobatan TB Paru adalah peran PMO. Oleh karena itu diperlukan pelatihan bagi kader-kader TB (PMO) untuk meningkatkan pengetahuan TB, kemampuan menjaring suspek TB dan membantu meningkatkan kepatuhan pengobatan.
\end{abstract}

Kata Kunci: Kepatuhan, Tuberculosis Paru

\begin{abstract}
Background: Patient adherence to taking medications is an important factor in the success of pulmonary TB treatment. The high rate of treatment dropouts results in a high number of cases of drug resistance. Methods: a case-control study design and involves primary and secondary data. Sample in this researchis is pulmonary TB patients being treated at Cipunagara Community Health Center in the duration of 2015 to June 2017. The sample size was 168 consisting of 84 cases and 84 controls, which wereselected by the consecutive sampling technique. Data analysis was univariate, bivariate with chisquare test, and multivariate with multiple logistic regression. Result: Factors related to pulmonary TB medication adherence are family support ( $p$-value $=0.003 ; O R=2.956)$, sex $(p$-value $=0.045$; OR = $1.961)$, education ( $p$-value $=0.045 ; O R=1.962)$, occupation $(p$-value $=0.043 ; O R=1.989)$, knowledge $(p$ value $=0.005 ; O R=2.529)$, drug side effects ( $p$-value $=0.045 ; O R=1.961)$, role of a drug-taking supervisor $(p$-value $=0.000 ; O R=3.500)$, distance to health facility $(p$-value $=0.044 ; O R=1.967)$, and attitude of health workers ( $p$-value $=0.020 ; O R=2.172)$. Factors that are not related are income ( $p$-value $=0.164)$ and age ( $p$-value $=0.535)$. Conclusion: The dominant factor associated with adherence to pulmonary TB treatment is role of a drug-taking supervisor. Therefore, training is needed to improve their knowledge of TB, their ability to identify TB suspects and help to improve their adherence to taking medications.
\end{abstract}

Keywords: Adherence, Pulmonary Tuberculosis. 
Pendahuluan

Tuberkulosis (TB) merupakan penyakit yang tinggi penularannya disebabkan oleh kuman Mycobacterium Tuberculosis dimana sebagian besar kuman TB menyerang paru, tetapi dapat juga mengenai organ tubuh lainnya. Sumber penularan dapat terjadi pada saat pasien dengan TB BTA positif (basil tahan asam) batuk atau bersin sehingga menyebarkan kuman ke udara (droplet nuclei). ${ }^{(1)}$

Hasil survei demografi dan kesehatan indonesia (SDKI) tahun 2012 menunjukan bahwa penyakit TB merupakan penyebab kematian nomor tiga setelah penyakit kardiovaskuler dan penyakit saluran pernafasan pada semua kelompok usia, dan nomor satu dari golongan penyakit infeksi. Sedangkan angka kejadian TB di Indonesia tahun 2014 mencapai 730 ribu kasus, dengan angka kematian yang cukup tinggisekitar 67 ribu,atau sekitar 186 orang tiap hari, atau 8 orang setiap jam, dari 189/100 ribu penduduk. Angka kejadian TB di Indonesia ini menyumbang sekitar 5,8\% kasus TB dari total jumlah kasus TB di dunia yang menempatkan Indonesia berada di urutan ke empat dengan beban TB terbesar di dunia (setelah India, China, Afrika Selatan). ${ }^{(2)}$ Lima provinsi dengan TB paru tertinggi adalah Jawa Barat (0.7\%), Papua
(0.6\%), DKI Jakarta (0.6\%), Gorontalo $(0.5 \%)$, Banten $(0.4 \%)$ dan Papua Barat $(0.4 \%) .{ }^{(3)}$

Laporan Tahunan Dinas Kesehatan Provinsi Jawa Barat Tahun 2012, diperoleh data dan informasi jumlah penderita TB paru pada tahun 2012 sebesar 62.218 kasus, dengan BTA positif sebesar 34.123 kasus. Target nasional untuk CDR adalah $70 \%$ dan angka kesembuhan (cure rate) minimal 85\%. CDR di Jawa Barat adalah sebesar $46 \%$ pada tahun 2012. Untuk angka kesembuhan di Jawa Barat masih dibawah target yaitu sebesar $81 \%$. Kabupaten Subang merupakan kabupaten di wilayah Jawa Barat yang dengan angka kejadian TB cukup tinggi yaitu 1778 kasus dengan CDR 79,18 $\%$. Angka kesembuhan 93,30\%, dengan angka kesuksesan (Treatment Success Rate) 96,21\% dan pengobatan lengkap 2,92\%. ${ }^{(4)}$

Pengobatan TB diberikan dalam bentuk kombinasi dari beberapa jenis, dalam jumlah cukup dan dosis tepat selama 6-8 bulan, supaya semua kuman dapat dibunuh. Apabila paduan obat yang digunakan tidak adekuat (jenis, dosis, dan jangka waktu pengobatan), kuman TB akan berkembang menjadi kuman kebal obat. Walaupun telah ada cara pengobatan tuberculosis dengan efektivitas yang tinggi, angka 
kesembuhan masih lebih rendah dari yang diharapkan. Penyebab utama terjadinya hal tersebut adalah pasien tidak mematuhi ketentuan dan lamanya pengobatan secara teratur untuk mencapai kesembuhan sebagai akibat tingkat pengetahuan masyarakat yang rendah. ${ }^{(5)}$

Kepatuhan pasien dalam minum obat merupakan faktor penting dalam keberhasilan suatu pengobatan. Ketidakpatuhan penderita TB paru merupakan penyebab terpenting kegagalan pengobatan tuberkulosis yang menjadi hambatan untuk mencapai kesembuhan. Pengobatan TB paru yang lama sering membuat pasien bosan dan menimbulkan ketidakpatuhan pasien dalam minum obat. $^{(6)}$

Faktor yang mempengaruhi kepatuhan penderita TB Paru dalam pengobatan dapat berasal dari internal maupun eksternal penderita. Beberapa penelitian menyebutkan bahwa pendidikan, pengetahuan, penghasilan dan jarak tempuh berpengaruh terhadap kepatuhan berobat pada pasien TB Paru. ${ }^{(7),(8)}$

Puskesmas Cipunagara merupakan Puskesmas di wilayah Kabupaten Subang. Berdasarkan peringkat TB kabupaten Puskesmas, Cipunagara menduduki peringkat 10 Puskesmas dengan penyakit TB paru terbanyak setelah Ciasem, Kalijati, Sukarahayu, Pamanukan dan Purwadadi Jumlah kasus TB 3 tahun terakhir mengalami kenaikan yaitu pada tahun 2014 sebanyak 57 kasus yang terdiri dari 10 kasus lama dan 37 kasus baru. Tahun 2015 sebanyak 66 kasus yang terdiri dari 22 kasus lama dan 44 kasus baru. Tahun 2016 sebanyak 87 kasus yang terdiri dari 47 kasus lama dan 40 kasus baru.

Berdasarkan masalah tersebut perlu dilakukan penelitian untuk mengetahui faktor-faktor yang berhubungan dengan kepatuhan pengobatan TB Paru di Puskesmas Cipunagara Subang.

\section{Metode}

Penelitian ini merupakan penelitian kuantitatif dengan desain studi kasus kontrol (Case Control Study) menggunakan data primer dan sekunder. Data primer antara lain : data demografi, efek samping obat, dukungan keluarga, peran $\mathrm{PMO}$, pengetahun dan sikap petugas. Data sekunder yang diperlukan antara lain : data jumlah pasien TB yang melakukan pengobatan dan data pasien gagal pengobatan. Penelitian ini dilakukan di wilayah kerja Puskesmas Cipunegara Subang pada bulan Juni-Juli Tahun 2017. Besar sampel dihitung dengan menggunkan rumus besar sampel uji hipotesis beda dua proporsi. Sampel 
dalam penelitian ini sebanyak 68 yang terdiri dari 84 kasus dan 84 kontrol yang diambil dengan teknik consecutive sampling. Kasus adalah pasien TB Paru yang tidak patuh pengobatan sedangkan Kontrol adalah pasien TB Paru yang patuh pengobatan pada

\section{Hasil}

\section{Tabel 1. Faktor-Faktor yang berhubungan dengan Kepatuhan Pengobatan TB}

\begin{tabular}{|c|c|c|c|c|c|c|}
\hline \multirow{3}{*}{ Variabel } & \multicolumn{4}{|c|}{ Kepatuhan Pengobatan } & \multirow{3}{*}{ Pvalue } & \multirow{3}{*}{$\begin{array}{c}\text { OR } \\
(95 \% \mathrm{Cl})\end{array}$} \\
\hline & \multicolumn{2}{|c|}{ Kasus } & \multicolumn{2}{|c|}{ Kontrol } & & \\
\hline & $\mathbf{n}$ & $\%$ & $\mathbf{n}$ & $\%$ & & \\
\hline \multicolumn{7}{|l|}{ Usia } \\
\hline Tidak Produktif (> 60 Tahun) & 16 & 19 & 12 & 14,3 & 0,535 & 1,412 \\
\hline Produktif (15-59 Tahun) & 68 & 81 & 72 & 85,7 & & $(0,623-3,201)$ \\
\hline \multicolumn{7}{|l|}{ Jenis Kelamin } \\
\hline Laki-laki & 50 & 59,5 & 36 & 42,9 & 0,045 & 1,961 \\
\hline Perempuan & 34 & 40,5 & 48 & 57,1 & & $(1,062-3,622)$ \\
\hline \multicolumn{7}{|l|}{ Pendidikan } \\
\hline Rendah (SD,SLTP) & 47 & 56 & 33 & 39.3 & 0,045 & 1,962 \\
\hline Tinggi (SLTA,PT) & 37 & 44 & 51 & 60,7 & & $(1,063-3,628)$ \\
\hline \multicolumn{7}{|l|}{ Pekerjaan } \\
\hline Tidak bekerja & 43 & 51,2 & 29 & 34,5 & 0,043 & 1,989 \\
\hline Bekerja & 41 & 48,8 & 55 & 65.5 & & $(1,069-3,700)$ \\
\hline \multicolumn{7}{|l|}{ Pengetahuan } \\
\hline Kurang & 55 & 65,5 & 36 & 42,9 & 0,005 & 2,529 \\
\hline Baik & 29 & 34,5 & 48 & 57,1 & & $(1,355-4,718)$ \\
\hline \multicolumn{7}{|l|}{ Pendapatan } \\
\hline Rendah & 50 & 59,5 & 40 & 47,6 & 0,164 & 1,618 \\
\hline Tinggi & 34 & 40,5 & 44 & 52,4 & & $(0,878-2,980$ \\
\hline \multicolumn{7}{|l|}{ Dukungan Keluarga } \\
\hline Tidak Mendukung & 67 & 79,8 & 36 & 42,9 & 0,003 & 2,956 \\
\hline Mendukung & 17 & 20,2 & 48 & 57,1 & & $(1,489-5,867)$ \\
\hline \multicolumn{7}{|l|}{ Efek samping obat } \\
\hline Ada & 48 & 57,1 & 34 & 40,5 & 0,045 & 1,961 \\
\hline Tidak ada & 36 & 42,9 & 50 & 59,5 & & $(1,062-3,622)$ \\
\hline \multicolumn{7}{|l|}{ Peran PMO } \\
\hline Kurang & 60 & 71,4 & 35 & 41,7 & 0,000 & 3,500 \\
\hline Baik & 24 & 28,6 & 49 & 58,3 & & $(1,842-6,651)$ \\
\hline \multicolumn{7}{|l|}{ Jarak Fayankes } \\
\hline Jauh $(\geq 5 \mathrm{Km})$ & 46 & 54,8 & 32 & 38,1 & 0,044 & 1,967 \\
\hline Dekat $(<5 \mathrm{Km})$ & 38 & 45,2 & 52 & 61,9 & & $(1,063-3,639)$ \\
\hline \multicolumn{7}{|l|}{ Sikap Petugas } \\
\hline Kurang baik & 47 & 56 & 31 & 36,9 & 0,020 & 2,172 \\
\hline Baik & 37 & 44 & 53 & 63,1 & & $(1,171-4,029)$ \\
\hline
\end{tabular}


Hasil penelitian menunjukkan bahwa pada kelompok kasus (tidak patuh pengobatan) sebagian besar berusia produktif $81 \%$, berjenis kelamin laki-laki $59,5 \%$, berpendidikan rendah (< SMA) 56\%, tidak bekerja 51,2\%, berpengetahuan kurang 65,5\%, berpendapatan rendah (<UMR) 59,5\%, tidak mendapatkan dukungan keluarga $79,8 \%$, menyatakan ada efek samping obat $57,1 \%$, menyatakan peran PMO kurang 71,4\% dan sikap petugas kurang baik 56\%. Analisis bivariat dengan uji chi square menunjukkan bahwa variabel usia (Pvalue $=0,535$ ) dan pendapatan (Pvalue $=0,164)$ tidak berhubungan dengan kepatuhan pengobatan TB paru. Variabel jenis kelamin (Pvalue $=0,045)$, pendidikan $(\mathrm{P}$ value $=0,045), \quad$ pekerjaan $\quad(\mathrm{P}$ value $=$
0,043), pengetahuan (Pvalue $=0,005$ ), dukungan keluarga (Pvalue $=0,003$ ), efek samping obat $(P$ value $=0,045)$, peran PMO (Pvalue $=0,000)$, jarak fasilitas kesehatan (Pvalue=0,044 dan sikap petugas (Pvalue $=0,020)$ berhubungan dengan kepatuhan pengobatan TB (Tabel 1).

Berdasarkan tabel 1, dari 11 variabel terdapat 10 variabel yang masuk dalam kandidat analisi multivariat (Nilai $\mathrm{p}=<\quad 0,25$ ) yaitu variabel pendapatan, dukungan keluarga, jenis kelamin, pendidikan, pekerjaan, pengetahuan, efek samping obat, peran $\mathrm{PMO}$, jarak fasilitas kesehatan dan sikap petugas kesehatan. Untuk selanjutnya analisa secara multivariat menggunakan regresi logistik model enter.

Tabel 2. Full Model Analisis Multivariat Faktor yang Berpengaruh dengan Kepatuhan Pengobatan TB Paru

\begin{tabular}{lcrcc}
\hline \multicolumn{1}{c}{ Variabel } & B & Pvalue & OR (Exp B) & 95\% Cl \\
\hline Pendapatan & 0,380 & 0,320 & 1,462 & $0,691-3,094$ \\
Dukungan keluarga & 0,706 & 0,087 & 2,026 & $0,903-4,547$ \\
Jenis kelamin & 0,352 & 0,367 & 1,422 & $0,662-3,055$ \\
Pendidikan & 0,398 & 0,308 & 1,489 & $0,693-3,197$ \\
Pekerjaan & 0,796 & 0,042 & 2,218 & $1,029-4,780$ \\
Pengetahuan & 0,594 & 0,134 & 1,811 & $0,832-3,942$ \\
Efek samping obat & 0,709 & 0,058 & 2,031 & $0,976-4,227$ \\
Peran PMO & 1,132 & 0,003 & 3,102 & $1,481-6,500$ \\
Jarak fasilitas kesehatan & 0,985 & 0,012 & 2,678 & $1,240-5,784$ \\
Sikap petugas kesehatan & 0,563 & 0,133 & 1,756 & $0,843-3,657$ \\
\hline
\end{tabular}

Tabel 2 menunjukkan bahwa setelah dilakukan analisis terhadap variabel yang masuk dalam seleksi multivariat terlihat bahwa 7 variabel yang tidak signifikan yaitu pendapatan (Pvalue $=0,320)$, dukungan keluarga
(Pvalue $=0,087), \quad$ jenis kelamin (Pvalue $=0,367)$, pendidikan (Pvalue= 0,308 ), pengetahuan (Pvalue $=0,134$ ), efek samping obat ( $P$ value $=0,058$ ) dan sikap petugas (Pvalue $=0,133$ ). Variabel yang memiliki nilai Pvalue > 
0,05 dikeluarkan dari model satu per satu dari Pvalue yang terbesar dan dilihat perubahan OR, jika mengakibatkan perubahan OR $>10 \%$ maka variabel tersebut diikutkan analisis selanjutnya.

Hasil akhir multivariat didapatkan bahwa variabel yang berhubungan signifikan dengan kepatuhan pengobatan pada pasien TB adalah dukungan keluarga, peran $\mathrm{PMO}$, dan jarak fasilitas kesehatan. Variable pendapatan, pendidikan, pekerjaan, pengetahuan dan efek samping obat merupakan variabel confounding.
Variabel dominan berhubungan dengan kepatuhan pengobatan adalah peran PMO dengan OR sebesar 3,355 (95\%Cl: 1,633-6,894), artinya pasien TB yang menyatakan peran PMO baik berpeluang 3,3 kali lebih besar untuk patuh diabandingkan dengan pasien TB yang menyatakan peran PMO kurang baik. Hasil persamaan regresi logistik berganda diperoleh $R^{2}$ sebesar 0,312 atau $31,2 \%$ artinya variabel tersebut diatas dapat menjelaskan kepatuhan pengobatan sebesar $31,2 \%$ sisanya dijelaskan oleh faktor lain (Tabel 3).

Tabel. 3. Model Akhir Faktor yang Berpengaruh dengan Kepatuhan Pengobatan TB Paru

\begin{tabular}{llrrrr}
\hline \multicolumn{1}{c}{ Variabel } & B & Pvalue & OR (Exp B) & 95\% Cl & $\mathbf{R}^{\mathbf{2}}$ \\
\hline Pendapatan $^{*}$ & 0,423 & 0,259 & 1,527 & $0,732-3,183$ & \\
Dukungan keluarga & 0,799 & 0,045 & 2,224 & $1,017-4,860$ & \\
Pendidikan* & 0,367 & 0,340 & 1,443 & $0,679-3,067$ & \\
Pekerjaan* $^{*}$ & 0,673 & 0,077 & 1,960 & $0,931-4,127$ & \\
Pengetahuan* & 0,682 & 0,079 & 1,978 & $0,925-4,231$ & 0,312 \\
Efek samping obat* & 0,638 & 0,081 & 1,893 & $0,924-3,877$ & \\
Peran PMO & 1,211 & 0,001 & 3,355 & $1,633-6,894$ & \\
Jarak fasilitas kesehatan & 1,137 & 0,003 & 3,117 & $1,485-6,544$ & \\
\hline \multicolumn{1}{c}{ Keterangan : $\left.{ }^{*}\right)$ faktor confounding } & & & &
\end{tabular}
Keterangan : $\left(^{*}\right)$ faktor confounding

Pembahasan

Hasil analisis hubungan usia dengan kepatuhan pengobatan diketahui tidak ada hubungan antara usia dengan kepatuhan pengobatan TB paru. Hasil ini berbeda dengan penelitian Primadiah pada tahun 2012 tentang hubungan karakteristik demografi dengan kepatuhan berobat pasien TB paru di RS Paru Jember, dimana diperoleh hasil uji bahwa usia berhubungan dengan kepatuhan
$\begin{gathered}\text { (Pvalue=0,004). }{ }^{(9)} \\ \text { Usia sesorang dapat }\end{gathered}$ mempengaruhi paparan penyakit. Semakin dewasa usia seseorang maka semakin matang dalam hal pencegahan penyakit. Namun pada kasus TB dapat menyerang siapapun dari berbagai umur. Dari beberapa hasil penelitian menunjukan bahwa sebagian besar kejadian TB terjadi pada usia 
produktif yaitu usia 15- 55 tahun. Usia produktif merupakan usia dengan masa aktivitas yang tinggi dan terpapar oleh lingkungan. Seharusnya pada usia ini seseorang harus sudah mampu mencegah TB, namun tidak semuanya menjalankan karena tingkat pemahaman yang berbeda. ${ }^{(10)}$

Persebaran usia pasien TB paru dalam penelitian ini menunjukan bahwa kelompok yang kurang patuh dalam berobat adalah usia produkif hal bisa saja terjadi karena kesibukan dalam beraktivitas. Selain itu bisa saja karena kurangnya motivasi yang kuat untuk memperhatikan kesehatanya.

Faktor jenis kelamin berhubungan dengan kepatuhan pengobatan TB paru. Hasil ini sejalan dengan penelitian Primadiah pada tahun 2012 tentang hubungan karakteristik demografi dengan kepatuhan berobat pasien TB paru di RS Paru jember, dimana jenis kelamin berhubungan dengan kepatuhan $(P$ value $=0,028) .{ }^{(9)}$

Perbedaan pola perilaku sakit juga dipengaruhi oleh jenis kelamin, perempuan lebih sering mengobatkan dirinya dibandingkan dengan laki-laki, sehingga akan lebih banyak perempuan yang datang berobat dibandingkan laki-laki. ${ }^{(11)}$ Laki-laki cenderung tidak patuh dibandingkan perempuan. Laki - laki lebih rentan terkena TB paru karena kurang memperhatikan kesehatan dan gaya hidup yang tidak sehat. ${ }^{(12)}$

Faktor pendidikan berhubungan dengan kepatuhan pengobatan TB paru. Hasil ini sejalan dengan Penelitian Kondoy dkk pada tahun 2014 di lima puskesmas di Kota Manado diperoleh hasil bahwa pendidikan berhubungan dengan kepatuhan berobat pasien TB Paru (Pvalue $=0,000){ }^{\left({ }^{(8)}\right.}$

Tingkat pendidikan seseorang sangat mempengaruhi perilaku hidup sehat. Seseorang dengan pendidikan yang rendah akan sulit dalam memahami informasi kesehatan yang diberikan oleh petugas kesehatan. Jika pasien TB tidak memahami mengenai manfaat minum obat secara teratur dan pemeriksaan teratur maka pasien akan putus berobat sehingga mengakibatkan resisten OAT. ${ }^{(10)}$

Semakin tinggi pendidikan seseorang maka semakin besar kemampuan untuk menyerap, menerima, atau mengadopsi informasi. Menurut Notoatmodjo bahwa pendidikan sejalan dengan pengetahuan, bila penderita TB paru tahu manfaat minum obat dengan teratur dapat membuatnya sembuh maka penderita tersebut akan patuh. ${ }^{(13)}$

Faktor pekerjaan berhubungan dengan kepatuhan pengobatan TB paru. Sejalan dengan Penelitian Aulia 
di Kecamatan Sakti Pidie menyatakan bahwa pekerjaan berhubungan dengan tingkat keberhasilan pengobatan TB pada pasien yang telah mendapatkan pengobatan (Pvalue $=0,012){ }^{(14)}$

Jenis pekerjaan menentukan faktor risiko apa yang harus dihadapi setiap individu, bila pekerja bekerja di lingkungan yang berdebu, paparan partikel debu akan mempengaruhi terjadinya gangguan pada saluran pernafasan. Paparan udara yang tercemar dapat meningkatkan morbiditas, terutama terjadinya gejala penyakit saluran pernafasan dan umumnya TB Paru. Jenis pekerjaan seseorang juga mempengaruhi terhadap pendapatan keluarga yang akan mempunyai dampak terhadap pola hidup sehari-hari diantara konsumsi makanan, pemeliharaan kesehatan selain itu juga akan mempengaruhi terhadap kepemilikan rumah (kontruksi rumah). ${ }^{(15)}$

Analisis peneliti bahwa lebih dari $57,1 \%$ responden dalam penelitian ini adalah status bekerja, hal ini mengindikasikan bahwa walaupun memiliki kesibukan aktivitas sehari-hari namun kesadaran untuk patuh dalam minum obat sangat diperhatikan. Hasil wawancara diketahui bahwa beberapa responden yang bekerja, namun pekerjaanya tidak mengikat waktu sehingga mereka mempunyai waktu untuk memanfaatkan pelayanan kesehatan dengan baik

Faktor pengetahuan berhubungan dengan kepatuhan pengobatan TB paru, Hal tersebut menunjukkan bahwa pengetahuan merupakan faktor penentu kepatuhan. Semakin baik pengetahuan seseorang maka semakin baik pula perilaku kesehatannnya dalam hal ini adalah kepatuhan berobat. Sejalan dengan penelitian Siswanto dkk pada tahun 2015 tentang hubungan pengetahuan dan dukungan keluarga dengan kepatuhan minum Obat Anti Tuberkulosis di Puskesmas Andalas Kota Padang (Pvalue $=$ 0,000). ${ }^{(16)}$ Penelitian Kondoy dkk pada tahun 2014 di lima Puskesmas di Kota Manado diperoleh hasil bahwa pengetahuan berhubungan dengan kepatuhan berobat pasien TB Paru (Pvalue $=0,000){ }^{(8)}$

Menurut Notoatmojo, tindakan seseorang terhadap masalah kesehatan pada dasarnya akan dipengaruhi oleh pengetahuan seseorang terhadap masalah tersebut, dalam hal ini semakin tinggi tingkat pengetahuan yang dimiliki klien TB maka semakin tinggi pula kepatuhan klien tersebut untuk melakukan pengobatan. Semakin rendah pengetahuan maka semakin tidak patuh klien TB untukminum OAT.(11) Seseorang yang memiliki pengetahuan 
tinggi kemungkinan besar akan lebih memanfaatkan fasilitas kesehatan yang ada, sehingga informasi tentang kesehatan akan mudah didapatkan. Tingginya pengetahuan seseorang terhadap penyakit akan mempengaruhi seseorang terhadap perilaku kesehatan. Seseorang yang berpengetahuan tinggi memiliki kesadaran diri yang tinggi akan kesehatan dan memiliki motivasi yang tinggi untuk sembuh. ${ }^{(17)}$

Hasil penelitian menunjukkan bahwa tidak ada hubungan antara pendapatan dengan kepatuhan pengobatan TB paru. Hasil ini berbeda dengan Penelitian Sutarji pada tahun 2006 tentang faktor yang berkaitan dengan kepatuhan penderita tuberkulosis paru untuk minum obat anti tuberkulosis pada pengobatan tahap insentif di Puskesmas Selomerto Wonosobo, yang menyatakan pendapatan berhubungan secara signifikan dengan kepatuhan penderita tuberkulosis paru untuk minum Obat Anti Tuberkulosis pada pengobatan tahap insentif (Pvalue=0,003). ${ }^{(18)}$ Serupa dengan penelitian Mirawati pada tahun 2013 yang menyatakan ada hubungan yang bermakna antara penghasilan dengan kepatuhan responden minum Obat Anti Tuberkulosis Paru (Pvalue=0,028). Responden yang memiliki penghasilan rendah mempunyai resiko 6,94 kali beresiko tidak patuh minum Obat Anti Tuberkulosis Paru dibandingkan dengan responden dengan penghasilan tinggi. ${ }^{(19)}$

Pendapatan yang rendah belum tentu mempengaruhi pemenuhan kebutuhan sehari-hari termasuk dalam mendapatkan pelayanan kesehatan yang memadai. Tingkat ekonomi yang rendah bukan menjadi hambatan bagi pasien TB dalan menjangkau fasilitas pelayanan kesehatan, saat ini di era BPJS semua masyarakat memperoleh kesempatan yang sama untuk mendapatkan pelayanan kesehatan, dan TB paru merupakan salah satu penyakit yang biaya pengobatannya tercover oleh BPJS, sehingga kepatuhan pengobatan TB tidak dipengaruhi oleh biaya (pendapatan).

Faktor dukungan keluarga berhubungan dengan kepatuhan pengobatan TB paru, hasil ini sejalan dengan penelitian yang dilakukan Sukmah di RSUD Daya Makassar menyatakan bahwa $70 \%$ pasien yang mendapatkan dukungan keluarga dan patuh dalam berobat. Ada hubungan yang signifikan antara dukungan keluarga dengan kepatuhan berobat pada pasien TB paru (Pvalue $=0,000) .{ }^{(20)}$ Penelitian Septia, Rahmalia dan Sebrian pada tahun 2013 di Rumah Sakit Umum Daerah Arifin 
Achmad menyatakan terdapat hubungan dukungan keluarga dengan kepatuhan minum OAT. ${ }^{(21)}$

Salah satu faktor yang dapat meningkatkan kepatuhan pengobatan pada penderita dengan penyakit kronik adalah adanya dukungan keluarga yang baik. Kepatuhan pengobatan ini meningkat ketika pasien mendapatkan bantuan dari keluarga. ${ }^{(22)}$ Penyakit TB mengharuskan pasien mengkonsumsi obat dengan jangka waktu yang lama, oleh karena itu diperlukan dukungan dari keluarga.

Efek samping obat berhubungan dengan kepatuhan pengobatan TB paru, sejalan dengan penelitian Sukmah dkk pada tahun 2013 menyatakan ada hubungan yang signifikan antara efek samping OAT dengan kepatuhan berobat pada pasienTB paru di RSUD Daya Makassar (Pvalue=0,000). ${ }^{(20)}$

Efek samping obat anti tuberkulosis diketahui merupakan salah satu fakor risiko terjadinya default. Efek samping obat antituberkulosis yang sering muncul adalah kehilangan nafsu makan, mual, sakit perut, nyeri sendi, kesemutan sampai dengan rasa terbakar di kaki dan warna kemerahan pada air seni. Efek samping yang lebih berat seperti gatal dankemerahan pada kulit, tuli, gangguan keseimbangan, gangguan penglihatan, ikterus tanpa penyebab lain, bingung dan muntahmuntah hingga purpura dan renjatan atau syok. Efek samping obat seperti tersebut di atas meningkatkan risiko ketidakpatuhan dalam berobat. Namun tidak semua efek OAT akan menimbulkan dampak buruk. ${ }^{(23)}$

Faktor peran $\mathrm{PMO}$ berhubungan dengan kepatuhan pengobatan TB paru. Hasil ini sejalan dengan penelitian Sukmah dkk pada tahun 2013 menyatakan ada hubungan yang signifikan antara peran pengawas menelan obat dengan kepatuhan berobat pada pasien TB paru di RSUD Daya Makassar dengan nilai signifikansi lebih kecil dari 5\% (Pvalue $=0,019)$. ${ }^{(20)}$

PMO adalah orang pertama yang selalu berhubungan dengan pasien sehubungan pengobatannya. PMO yang mengingatkan untuk minum obat, mengawasi sewaktu menelan obat, membawa pasien ke dokter untuk control berkala, dan menolong pada saat ada efek samping.

Sesuai dengan strategi DOTS, setiap pasien yang baru ditemukan dan mendapatkan pengobatan harus diawasi menelan obatnya setiap hari agar terjamin kesembuhan, tercegah dari kekebalan obat atau resistensi. Sebelum pengobatan pertama kali dimulai, pasien dan PMO harus diberi penyuluhan secara singkat tentang 
perlunya pengawasan menelan obat setiap hari. Penyuluhan tersebut meliputi gejala-gejala TBC, tanda-tanda efek samping obat, dan mengetahui cara mengatasi bila ada efek samping, cara merujuknya, kegunaan pemeriksaan sputum ulang, serta cara memberi penyuluhan TBC. ${ }^{(24)}$

Untuk menjamin kepatuhan pasien menelan obat, dilakukan pengawasan langsung oleh seorang PMO yang sebaiknnya datang dari masyarakat, bukan kalangan kesehatan yang jumlahnya terbatas.

Faktor jarak fasilitas kesehatan berhubungan dengan kepatuhan pengobatan TB paru. Hasil ini sejalan dengan penelitian Primadiah pada tahun 2012 menunjukan bahwa variabel jarak tempat tinggal pasien TB paru dengan RS Paru jember berhubungan secara sinifikan dengan kepatuhan berobat pasien TB paru $(p=0,000)$. Hasil uji statistik menunjukan bahwa penderita dengan jarak lebih dari $5 \mathrm{Km}$ lebih cenderung drop out dalam berobat, sehingga jarak tempat tinggal pasien TB Paru dengan pelayanan kesehatan memiliki hubungan yang bermakna dengan kepatuhan berobat. ${ }^{(9)}$

Semakin jauh jarak dari rumah pasien dari tempat pelayanan kesehatan dan sulitnya transportasi maka, akan berhubungan dengan keteraturan berobat. Kurangnya sarana transportasi merupakan kendala dalam mencapai pelayanan kesehatan. Pada penelitian yang dilakukan oleh Nandang Tisna dalam Prayogo pada tahun 2013 menyebutkan bahwa faktor jarak adalah suatu faktor penghambat untuk pemanfaatan pelayanan kesehatan. tersedianya sarana transportasi akan memberi kemudahan dalam mendapatkan pelayanan kesehatan. ${ }^{(7)}$

Semakin jauh jarak rumah kepala keluarga ke tempat pelayanan kesehatan semakin sedikit penggunaan pelayanan kesehatan. Kemudahan dalam akses menuju fasilitas kesehatan sangatlah memungkinkan seseorang untuk memanfaatkannya. Hal ini juga di kemukakan oleh Notoatmodjo dalam penjelasan persepsi sehat dan sakit, dimana dikatakan bahwa setiap seseorang yang sakit akan mecari pengobatan ke tempat yang dianggap dapat memberikan pengobatan sehingga bisa mencapai kesembuhan atas sakit yang dideritanya. Perilaku ini hampir dilakukan di setiap personal individu. ${ }^{(13)}$

Faktor sikap petugas kesehatan berhubungan dengan kepatuhan pengobatan TB paru. Didukung penelitian Mirawati pada tahun 2013 menyatakan ada hubungan yang 
bermakna antara Sikap Petugas

Kesehatan dengan kepatuhan responden minum Obat Anti Tuberkulosis Paru (Pvalue $=0,022)$. Responden yang menyatakan Sikap Petugas Kesehatan tidak mendukung mempunyai resiko 9,33 kali beresiko tidak patuh minum obat anti Tuberkulosis Paru dibandingkan dengan responden yang menyatakan Sikap Petugas Kesehatan mendukung. ${ }^{(19)}$

Sikap Petugas kesehatan berkaitan dengan interaksi antara petugas kesehatan dan pasien. Keterkaitan antara manusia yang baik menanamkan kepercayaan dan kredibilitas dengan cara menghargai yang dapat dilihat melalui penerimaan, kepercayaan, empati, menjaga rahasia, menghormati, dan responsif serta memberikan perhatian terhadap pasien. Peranan petugas kesehatan adalah memberi pelayanan kesehatan kepada masyarakat. Petugas kesehatan sebagai pengelola dalam program pemberantasan TB paru meliputi dokter, paramedis, juru TB, petugas mikroskopis. Hubungan antara petugas kesehatan dan penderita sangat berpengaruh terhadap keberhasilan pengobatan. Salah satu determinan perilaku kepatuhan berobat TBC paru adalah dukungan petugas kesehatan selama pengobatan TBC paru. ${ }^{(24)}$

\section{Kesimpulan}

Faktor dominan yang berhubungan dengan kepatuhan berobat pasien TB Paru adalah peran PMO. Untuk itu diharapkan Puskesmas mengadakan pelatihan bagi kader-kader TB (PMO) untuk meningkatkan pengetahuan tentang $\mathrm{TB}$, kemampuan menjaring suspek TB dan membantu meningkatkan kepatuhan minum obat pasien TB.

\section{Ucapan Terima Kasih}

Penulis mengucapkan terima kasih kepada institusi Puskesmas Cipunegara Subang dan semua pihak yang berkonstribusi dalam proses pengumpulan data.

\section{Daftar Pustaka}

1. Kemenkes RI. Strategi Nasional Pengendalian TB di Indonesia 2010-2014. Jakarta; 2011.

2. Kemenkes RI. Survei Demografi dan Kesehatan Indonesia (SDKI) 2012 [Internet]. Jakarta; 2013. Available from: http://kesga. kemkes.go.id/images/pedoman/SD KI 2012-Indonesia.pdf

3. Kemenkes RI. Riset Kesehatan Dasar (RISKESDAS) 2013 [Internet]. Jakarta; 2013. Available from: http://www.depkes.go.id/ resources/download/general/Hasil Riskesdas 2013.pdf 
4. Dinas Kesehatan Provinsi Jawa Barat. Laporan Tahunan Dinas Kesehatan Provinsi Jawa Barat. Bandung; 2012.

5. Fitria CN, Mutia A. Hubungan tingkat pengetahuan tentang tuberkulosis dengan kepatuhan minum obat di puskesmas. Jikk. 2016;7(6):41-5.

6. Pasek MS, Suryani N, Murdani P. Hubungan Persepsi dan Tingkat Pengetahuan Penderita Tuberkulosis Dengan Kepatuhan Pengobatan di Wilayah Kerja Puskesmas Buleleng 1. Magister Kedokt Kel. 2013;1(1):14-23.

7. Prayogo AHE. Faktor-Faktor Yang Mempengaruhi Kepatuhan Minum Obat Anti Tuberkulosis Pada Pasien Tuberkuloasis Paru di Puskesmas Pamulang Kota Tangerang Selatan Provinsi Banten Periode Januari 2012-Januari 2013. 2013;

8. Kondoy PPH, Rombot D V., Palandeng HMF, Pakasi TA. Faktor-Faktor Yang Berhubungan Dengan Kepatuhan Berobat Pasien Tuberkulosis Paru di Lima Puskesmas di Kota Manado. J Kedokt Komunitas dan Trop. 2014;II:1-8.

9. Primadiah N. Hubungan Karakteristik Demografi dengan
Kepatuhan Beobat Pasien TB Paru di RS Paru Jember.Skripsi. 2012.

10. Linda DO. Hubungan Karakteristik Klien Tuberkulosis dengan Pengetahuan Tentang Multidrugs Resisten Tuberkulosis di Poli Paru Puskesmas Kecamatan Jagakarsa. Skripsi. 2014;

11. Notoatmodjo S. Pendidikan dan Perilaku Kesehatan. Jakarta: PT Rhineka Cipta; 2007.

12. Erawatyningsih E, Purwanta, Subekti H. Faktor-Faktor yang Mempengaruhi Ketidakpatuhan Berobat pada Penderita Tuberkulosis Paru. Ber Kedokt Masy [Internet]. 2012;25(3):117. Available from: https://journal. ugm.ac.id/bkm/article/view/3558

13. Notoatmodjo S. Promosi Kesehatan dan IImu Perilaku. Jakarta: PT Rhineka Cipta; 2012.

14. Aulia Y. Hubungan umur, jenis kelamin, dan pekerjaan dengan keberhasilan pengobatan tuberkulosis pada pasien yang telah mendapat pengobatan di Kecamatan Sakti, Pidie [Internet]. Universitas Syah Kuala Darusalam.; 2014. Available from: http://etd.unsyiah.ac.id/index.php?p =show_detail\&id=4522

15. Ketouki A. Gambaran perilaku penderita dan risiko tuberkuloasis 
BTA positif dengan kepatuhan minum obat dan kebiaasaan membuang dahak di wilayah Puskesmas Ciomas Kabupaten Bogor Jawa Barat Tahun 2012. Skripsi. 2012;

16. Siswanto IP, Yanwirasti, Usman E. Hubungan Pengetahuan dan Dukungan Keluarga dengan Kepatuhan Minum Obat Anti Tuberkulosis di Puskesmas Andalas Kota Padang. J Kesehat Andalas. 2015;4(3):724-8.

17. Noorhizmah $\mathrm{RH}$, Rekawati $\mathrm{E}$ Hubungan Tingkat Pengetahuan Klien Tuberkulosis dengan Kepatuhan Minum Obat Anti Tuberkulosis. 2016;1-7.

18. Sutarji. Beberapa Faktor Yang Berkaitan Dengan Kepatuhan Penderita Tuberkulosis Paru Untuk Minum Obat Anti Tuberkulosis Pada Pengobatan Tahap Insentif $\mathrm{Di}$ Puskesmas Selomerto Wonosobo [Internet]. Universitas Diponegoro; 2006. Available from: http://eprints. undip.ac.id/38138/

19. Mirawati. Faktor - Faktor Yang Berhubungan Dengan Kepatuhan Klien Minum Obat Pada Klien Tb Paru Di Ruang Poli Penyakit Dalam Rsud Kepahiang Tahun 2013. STIKES Muhammadiyah
Semarang; 2013.

20. Sukmah; Mahyudin; Suarnianti. Faktor - faktor yang berhubungan dengan kepatuhan berobat pada pasien tb paru di rsud daya makassar. 2013;2:76-84. Available from: ejournal.stikesnh.ac.id/index. php/jikd/article/download/466/347\% $0 A \% 0 A$

21. Septia A, Rahmalia S, Sabrian F. Hubungan dukungan keluarga dengan kepatuhan minum obat pada penderita tb paru. Jom Psik. 2013;1(2):1-10.

22. Glick ID, Stekoll AH, Hays S. The role of the family and improvement in treatment maintenance, adherence, and outcome for schizophrenia. $\mathrm{J}$ Clin Psychopharmacol. 2011;

23. Kemenkes RI. Pedoman Nasional Penanggulangan Tuberkulosis. In Jakarta: Direktorat Jendral Pengendalian Penyakit dan Penyakit Lingkungan Kemenkes RI; 2011. Available from: http://www.dokternida.rekansejawat .com/dokumen/DEPKES-PedomanNasional-Penanggulangan-TBC2011-Dokternida.com.pdf

24. Murtiwi. Keberadaan Pengawas Minum Obat ( PMO ) Pasien. J Keperawatan. 2005;10(1):11-5. 